\section{Book of the month Public Health at the Crossroads: Achievements and Prospects}

In 2001 I gave the Harben Lecture of the Royal Institute of Public Health taking as my title 'Knowing is not enough'. My theme was the gap between the science of public health (especially epidemiology) and its national and global application, and the phrase, already borrowed by the US Institute of Medicine for its report Crossing the Quality Chasm, came from Goethe:

'Knowing is not enough, we must apply,

Willing is not enough, we must act.'

These sentiments would make an equally appropriate preface to Beaglehole and Bonita's Public Health at the Crossroads - an ambitious and provocative work now in its second edition. ${ }^{1}$ The work is ambitious in offering an account of public health science, policy and practice from both longitudinal (historical) and latitudinal (global) perspectives and at the same time attempting to see a way forward for the discipline. It is provocative in arguing that much of the failure of both epidemiology and public health to fulfil their potential can be blamed on the public health professions, who have become too narrowly focused on the medical aspects of public health and especially the organization and cost containment of medical services.

Public health practitioners in the UK may well smile wrily at the idea that their discipline is at the crossroads. Many must feel that, at least in terms of structure, a crossroads was reached some time ago and that different parts of our 'United' Kingdom chose different paths. Most, however, will acknowledge that the route that takes us eventually to the sunny uplands of full effectiveness will be punctuated by further crossroads - more, indeed, than are comfortable for those who wish to see a certain way ahead. In their masterly and intensively referenced sweep of the history of public health, Beaglehole and Bonita themselves document periods of epidemiological transition that have provided major crossroads for public health policy and practice - an era of pestilence and famine; giving way to an era of receding pandemics; followed by an era of noncommunicable diseases; and now the beginning of an era in which old infectious diseases make a come-back, new ones emerge and non-communicable diseases stubbornly persist.

A question that recurs almost as a motif in Public Health with the application of knowledge to individual patients, public health is failing society by neglecting the social and economic influences upon health and disease. Admittedly this second route for the discipline is thick with political and commercial brambles. Taking a global perspective and acknowledging that different countries are at different stages in their epidemiological transition, Beaglehole and Bonita see the need for a short and succinct definition of public health that is 'broad in scope and wide in appeal'. The definition they propose is 'Collective action for sustained population wide health improvement'. Certainly it meets their criteria, but am I alone in finding Acheson's version - 'The art and science of preventing disease, promoting health and prolonging life through the organised efforts of society' - more comprehensive, more appealing and very much more elegant (as well as lacking the stalinist overtones)?

How does all this fit with the matters that will be uppermost in the minds of most British readers of the new edition. Sir William Stewart has advised that 'we have to look on things globally but not get lost in global issues'. I have referred already to the crossroads recently passed in terms of structural change. Will the differing paths taken at devolution in England, Scotland, Wales and Northern Ireland mean that public health practitioners in one or more of those countries will find themselves wandering in the wilderness? Or will they prove to be merely short parallel roads that come together as the map becomes clearer? Still more to the point, does the recent awakening of interest by both public and policy makers in public health, stimulated by epidemiology in the form of authoritative reports on obesity and smoking and evidenced by the production of the Wanless reports (commissioned, interestingly, by the Treasury rather than the Health Department) offer a new broad highway for colleagues in the UK to follow? Is Sir Derek Wanless right in his view that 'the real knowledge and skill to take forward the public health agenda lies at local level'? To respond to his report Securing Good Health for the Whole Population will be a complex task, but he warns that a failure of the public health movement to rise to the opportunity will lead to lasting regret. Moreover, by reiterating the message of his first report, that 'public health is good economics,' he provides the discipline with a scythe to cut a path through the brambles referred to previously.

But has the dispersal of expertise (likely to be accentuated in England by the abolition of health authorities, though averted in Wales by the creation of a Wales-wide Public Health Service) weakened the ability of the discipline to wield this weapon effectively? And does not Wanless's emphasis on the need for the population to be 'fully engaged in the pursuit of good health' somewhat smack of the victim-blaming that Beaglehole and Bonita castigate as a governmental excuse for inaction? It is a 
disappointment that neither Beaglehole and Bonita in the book nor Wanless in his report tackle the means by which government departments other than Health might be held to account for the effects of their policies on population health. Without such accountability the efforts, however valiant, of the public health community at local level will prove too puny to be fully effective. What a pity that Wanless failed to tackle the glaring anomaly whereby the Secretary of State for Health in Whitehall is almost exclusively concerned with the Health Service whereas a junior Minister holds the public health portfolio. If it were the other way round (i.e. acknowledging that the NHS is essentially a tool of public health) such accountability might come closer to reality - though admittedly it is hard to imagine any Health Secretary becoming sufficiently powerful within Cabinet to demand real accountability from the likes of the Chancellor, the Environment Secretary or the Employment Secretary. The belated recognition that good public health is good economics cries out, therefore, for the establishment of a body on the lines of and with similar powers to the National Audit Office and the Parliamentary Accounts Committee. A National Office of Audit of Health (with the not inappropriate acronym $\mathrm{NOAH}$ ) would symbolize the UK Government's understanding that the population's health is at least as precious a resource as its finances. And the same may be even more true of countries with less abundant resources.

Having provided a wide-ranging, admirably evidencebased and often daunting and gloomy account of public health status and public health endeavours globally, Public Health at the Crossroads ends on a cautiously optimistic note. This optimism is based on Beaglehole and Bonita's assessment that the economic pendulum will swing back towards a more collectivist approach as the ill-effects of the free market are recognized, and that the public health movement will then find more opportunities to exert a central role in human affairs. One does not have to embrace whole-heartedly their political philosophy to hope that their optimism is justified.

\section{Deirdre Hine}

12 Mill Road, Llanishen, Cardiff CF14 OXB, Wales, UK

\section{REFERENCE}

1 Beaglehole R, Bonita R. Public Health at the Crossroads: Achievements and Prospects, 2nd edn. Cambridge: Cambridge University Press, 2004 [303 pp; ISBN 0-521-54047-X (p/b); £27.95]

\section{Principles of Medicine in Africa}

Third edition

Editors: E Parry, R Godfrey, D Mabey, G Gill

1442 pp Price £120 ISBN 0-521-80616-X (h/b)

Cambridge: Cambridge University Press

\section{Textbook of Tropical Surgery}

Editors: R Kamel, J Lumley

1332 pp Price £193.50 ISBN 0-9546855-0-4 (h/b)

London: Westminster Publishing

Principles of Medicine in Africa, in its radically revised third edition, is an excellent volume; one of the few drawbacks is its weight (nearly $5 \mathrm{~kg}$ ). One need go no further than the contents pages to see the clarity of thought and the consistency in design, and the introductory chapters are witness to the editors' understanding of human ecology in Africa. Over a hundred individual contributors represent experience gathered in various African regions and settings. It is obvious that they were given precise instructions, and the chapters are characterized by concise text, excellent photographs, ingenious tables, easy-to-read maps and a multitude of references. This volume, indeed, is more deserving of the designation 'textbook' than the second book reviewed here, Kamel and Lumley's Textbook of Tropical Surgery. In the surgical volume - which begins with a mission statement in nine languages anticipating the formation of the Global Academy of Tropical Surgery - the essays vary much more in quality of content, language, and illustrative material, with less generous use of colour. The reader, instead of being supplied with references, is directed to 'further reading'. Perusing the table of contents one is struck by titles such as 'Hearing impairment in ancient Egypt', 'Living systems and dynamic complexity' and 'Robotics in videoscopic surgery' that have no obvious connection with the main topic. Many chapters, indeed, have scant relevance to surgery, such as those on viral fevers (haemorrhagic and non-haemorrhagic), yellow fever and legionnaires' disease. There are frequent duplications: for instance, yellow fever is one of the viral haemorrhagic fevers; tetanus is dealt with extensively in a gynaecological/obstetric chapter but has its own chapter as well. With duplications of this kind, contradictions inevitably creep in. 
Unlike the physicians, the surgeons (in excess of 250 contributors) seem to have been given a more or less free hand-sometimes with bizarre results. The chapter on anaesthesia is glaringly inadequate, for it offers no practical guidelines at all. Other chapters are distinguished by loquacity, and the prize for chattiness goes to an item on warm-blood-animal bites in the section grandly called 'Tropical morsology'. In this chapter, which sounds like stories told around a campfire, we learn of the man-eating lions of Tsavo, man-eating tigers and leopards. It also has a paragraph on elephants, and another in which the rhino and the hippo are married. We are told the size and weight of many species (and the bountiful flora of their mouths) but there is little useful information about treatment. Obviously a big animal can do more damage than a small one but a bite is a bite. Incidentally, rhinos gore and toss but do not bite. The discussion of snakebites, on the other hand, is much better in the surgical book than in the medical volume. The medical contributor is fixated on snake identification and antivenoms, whereas the surgical author is looking at the victim rather than the snake. This syndromic approach is very sensible: most people are not herpetologists, able to identify the snake that bit them; about a third of snakebite victims are children, and many are bitten at night. Moreover, in the rare instance when the poor snake is killed and taken to the hospital, the staff are unlikely to identify it. A drawback of antivenoms is that they are not available: production is low, they are expensive and they have a limited shelf-life. Also antivenoms can kill faster than venoms. All in all, less than $10 \%$ of people admitted to hospital with snakebites would benefit from treatment with antivenom.

The snakebite chapter is not the only one that is better in the surgical book. The physicians are strangely tightlipped about cancer: the general attitude seems to be that cancers are less frequent in Africa than in western countries and that if they occur they have a near hopeless prognosis. Also there appears to be no appreciation of the fact that some cancers, colonic and rectal for instance, have become very common among urban dwellers in Africa and that young people are affected.

If the neglect of cancers by the physicians is the result of an editorial decision, the defects in the surgical book stem from lack of editorial direction. Oropharyngeal cancer surgery is allotted pages of detail — of procedures in fact which will be beyond the scope of the readers. On the other hand, mastectomy is not described at all (ironically, reduction mammoplasty is). The medical volume is strong in ecology and geography, the surgical volume in historyespecially Egyptian history, doubtless because more than a third of the contributors are from Egypt. History is always interesting and it may contribute to understanding; still, it account of a mummy that has been found to have had a vesicovaginal fistula.

What of the indexes? It is seldom one encounters a book that is well indexed. To find an entry only to be told to 'see under' something else is a bitter experience, exceeded in bitterness only if one cannot find at all what one is looking for. Editors of textbooks ought to attend to this matter, for bad indexing can compromise useability. The medical volume is the better indexed. In the surgical book one finds the usual fare awaiting the index user: under Donovanosis one finds 'see Leishmania donovani'; under Leishmania donovani one finds 'granuloma inguinale', which has nothing to do with Leishmania. Further under Leishmania donovani the index lists 'granuloma venereum', an entity that has nothing to do with either Leishman or Donovan.

One has compassion with Professor Kemal and Professor Lumley, the surgeon editors, who embarked on a task never undertaken before. Both are much-travelled ex-Presidents of the International College of Surgeons, but only Kemal has extensive experience of working in the tropics, and that mainly in Egypt. They relied on a network of acquaintances of the kind one meets at conferences and did not exert sufficient editorial control. All along there was something messianic in this undertaking and it miscarried. A great pity, for many people worked so hard. The physicians, with their solid grounding in tropical Africa, a sharper focus and a comprehensive editorial policy, produced a much better tome - one that is, with respect to Africa, better even than Manson's Tropical Diseases.

\section{Imre Loefler}

Nairobi Hospital Proceedings, Editorial Office, PO Box 30026-00100, Nairobi, Kenya

\section{Gynaeoncology Palliative Care Consultations}

Editors: Sarah Booth and Eduardo Bruera

$176 \mathrm{pp}$ Price £19.95 ISBN 0-19-852806-X (p/b)

Oxford: Oxford University Press

On seeing the word 'consultations' in the title I was gloomily expecting a series of case scenarios. The book is in fact much better than this. The first three chapters deal with advanced cancer of the cervix, ovary and endometrium (surprisingly there is no fourth chapter on vulval cancer). The remaining nine address specific complications such as pelvic pain, malodorous discharges and fistulae, and each provides an excellent resource for anybody who deals with advanced gynaecological cancer. I particularly liked the chapter on odours and discharges. Smell is a very powerful sense and one we are socially precluded from discussing; yet bad smells are among the most debilitating and devastating troubles for patients. The authors discuss the wide range of 
causes and offer numerous excellent suggestions for management. My only slight criticism is that they say nothing about the use of interventional radiology/ nephrostomies to redirect urine and thus obviate odour in a terminally ill woman. In summary, having picked up the book with low expectations I discovered a helpful text to which I shall be referring many times in the future.

\section{J Richard Smith}

Chelsea and Westminster Hospital,

London SW10 9NH, UK

\section{The Epidemiological Approach}

Nicholas $\mathrm{J}$ Wald

$86 \mathrm{pp}$ Price £8.95 ISBN 1-85315-58-5 (p/b)

London: RSM Press

Modern medicine is founded on epidemiological concepts but epidemiology itself tends to be unpopular with medical students. Despite efforts to brighten the teaching, many students still find the subject tedious and hard to grasp. For these, I recommend The Epidemiological Approach, which Professor Wald originally wrote for students in his own school (Barts). Its small size belies the wide-ranging content, and the style of writing is engaging. All the major areas of epidemiology are covered - from study design to birth and death patterns - and his explanations of concepts such as relative risk, likelihood ratio and prevalence are coupled with easy-to-follow examples and advice on how to calculate as well as interpret them. Statistical analysis of raw data is dealt with briefly but broadly. The subject matter even includes death certification - a task feared by many a new house officer. With its focus on the basics, its perfect balance of information and its readability The Epidemiological Approach is a book that no medical student should be without.

\section{Mark Hohenberg}

Student Members' Group, RSM

\section{Is it in your Genes? The Influence of Genes on Common Disorders and Diseases that affect you and your Family}

Philip R Reilly

288 pp Price US\$19.95 ISBN 0-87969-721-0 (p/b)

Woodbury, NY: Cold Spring Harbor Laboratory Press

Though Dr Reilly's book is targeted at scientifically literate laymen, I think it will be of greatest value to non-geneticist clinicians who occasionally face difficult questions about conditions that seem to run in a patient's family. An accompanying website promises to keep the information up to date and, if this commitment is sustained, this will be a really useful resource. As one might expect from a book from Cold Spring Harbor Laboratories, the examples provided are geared to healthcare delivery in the US. The British reader might have appreciated a list of contact numbers for NHS regional genetics centres who can be consulted by those in need of further guidance: such a list is obtainable from the British Society for Human Genetics [www.bshg.org.uk].

For the general public, I suspect this will be a work to consult rather than purchase. Those who do dip into itand find information on the genetics of conditions ranging from homosexuality (2-3 times the background risk if you have a gay brother) and male pattern baldness to cancers and heart disease - will quickly realize that the deterministic view of genetics that is often conveyed by the media, with announcements of 'a gene for $\mathrm{x}$ or $\mathrm{y}$ ' where these are complex behaviours or multifactorial diseases, is a gross oversimplification. If that message can be lodged in the reader's mind then the author will have done everyone a favour.

For clinicians, the impact of genetics on clinical practice outside the specialist area of the rare single gene disorders (or the Mendelian subsets of some of the common ones) has so far been small, but this will soon start to change and they will have to master the complexities of genetic and environmental interactions. Whilst Reilly's book is no substitute for proper professional development programmes, its clarity and its easy and accessible style will help them meet this challenge and provide sensible advice.

\section{Alastair Kent \\ Genetic Interest Group, London N1, UK}

\section{Investigative Rhinology}

Glenys K Scadding, Valerie J Lund

153 pp Price £75 ISBN 1-84184-197-8 (h/b)

London: Taylor \& Francis

In their small but comprehensive publication Dr Scadding and Professor Lund offer a host of useful insights for the budding rhinologist with an eye on research, as well as the fruits of their extensive experience in the clinical setting. Their book is mainly about rhinitis, and they begin by emphasizing the heavy toll of this disorder in the general population. From there we proceed to aetiology and pathology. They remind us, when evaluating patients with this disorder, to think of predisposing factors such as betablockers. The next two chapters tackle history and examination - as in most other patients, the most important part of assessment - and we are then treated to a detailed 
synopsis of the current investigations and research tools available to the rhinologist, including sometimes forgotten components such as olfaction and cerebrospinal fluid testing. In these final chapters, abundant flow charts, graphs and clinical pictures provide a backdrop to the text. Some of these might be regarded as superfluous, but certainly not those in the chapter on imaging, where radiological and endoscopic findings are compared. This volume will be enjoyed by any clinician with an interest in rhinitis and, with its detailed attention to research-based investigation, will be a boon to rhinological researchers. Non-specialists who encounter the disorder will also glean useful information, especially from the early chapters. Admittedly there is scant attention to disorders other than rhinitis, but the focus is made clear in the opening chapter. A particularly valuable component for researchers is the contact information and addresses for research equipment. If only I had had these to hand in the past! The only real drawback of the book is the price.

\section{Carl Philpott}

Norfolk \& Norwich Hospital, Norwich NR4 7UY, UK

\section{Medical Ethics and the Elderly}

Second edition

Gurcharan S Rai

163 pp Price £19.95 ISBN 1-85775-851-X (p/b)

Abingdon: Radcliffe Medical Press

In most specialties healthcare professionals are treating increasing numbers of elderly patients. Often the management decisions go far beyond diagnosis and treatment, demanding a knowledge of ethics as well as the law. The publication of an updated edition of Medical Ethics and the Elderly is particularly timely in view of developments such as the Human Rights Act 1998, the draft bill on mental incapacity and new guidelines on cardiopulmonary resuscitation. It begins with the obligatory chapters on principles of ethics, confidentiality, consent and mental incapacity, and these form the basis for the discussion of ethical issues in clinical work. Most of the chapters, indeed, deal with specific difficulties commonly encountered in the management of older patients. Chapters on stroke and dementia are very comprehensive and offer guidance on many of the clinical dilemmas that arise in treatment of these common conditions. Other particularly noteworthy chapters are those on life-sustaining therapy, cardiopulmonary resuscitation, advance directives and achieving a good death.

The style and layout is user-friendly. Most chapters can be read in isolation, allowing the reader to dip into an area of interest; key points at the end of every chapter highlight what is to be learned. All difficult ethical decisions must be taken within the legal boundaries, and many chapters include useful summaries of the law of the land. Where opinions differ - for example, on the matter of achieving a good death - the various points of view are sensitively and fairly described. This impartial approach will help clinicians to understand points of view different from their own. Some chapters include algorithms that allow for those difficult circumstances where personal opinions (including those of relatives), ethical issues and legalities must all be taken into account. Particularly useful are those relating to initiation of feeding, cardiopulmonary resuscitation and lifesustaining treatment. If there is room for improvement, it is in the discussion of some of the illustrative cases - too simplistic in my opinion.

Medical Ethics and the Elderly will appeal primarily to professionals working in general and geriatric medicine, though much of it is of general interest. Examination candidates may well find it useful, now that ethics is being included in undergraduate and postgraduate curricula. I personally found the book informative and enjoyable, and will be keeping it handy for reference.

\section{Michael Vassallo}

Royal Bournemouth Hospital, Bournemouth BH7 7DW, UK 